\title{
TRANSMISSION BIASES IN LINGUISTIC EPIDEMIOLOGY ${ }^{1}$
}

\author{
Nicholas J. Enfield \\ Max Planck Institute for Psycholinguistics, Nijmegen
}

To develop a nuanced account for selection within an epidemiological, population-based model of language contact and change, it is useful to consider possible conduits and filters on linguistic transmission and distribution. Richerson \& Boyd (2005) describe a number of candidate biases in their evolutionary analysis of culture as a biological phenomenon (cf. Cavalli-Sforza \& Feldman 1981, Sperber 1985, 1999, Boyd \& Richerson 2005). This paper explores some of these biases with reference to language, exploring a set of analytic distinctions for a proper understanding of population-level linguistic processes. In putting forward these ideas, this paper echoes recent attempts to combine linguistic and biological concepts in the analysis of language diversity and change.

\section{Background}

The perspective put forward here arose in the course of large-scale empirical work on patterns of grammaticization of aspect-modality markers in languages of mainland Southeast Asia (MSEA; Enfield 2003). The MSEA area (Laos, Thailand, Vietnam, Cambodia, and bordering areas) presents the most extreme case of grammatical convergence in the world, 'the ultimate Sprachbund' according to Dahl's measure of genealogical diversity relative to typological diversity (Dahl 2006; cf. Enfield 2005). There are at least five language families represented in this area (Tai, Austroasiatic, Hmong-Mien, Sino-Tibetan, Austronesian), yet on a broad range of typological measures, a comparison between two languages from distinct families-e.g., Thai (Tai) and Hmong (Hmong-Mien) - yields a structural similarity score around the same as for two languages low in the same branch of a single family elsewhere in the world (e.g., English and German, both West Germanic).

Enfield (2003) presents a detailed comparison of the semantic and grammatical properties of a

\footnotetext{
${ }^{1}$ I thank contributors to the symposium «Language contact and the dynamics of language: Theory and implications» at MPI EvA in Leipzig, May 2007 for comments and discussion of this work, and especially Robert Nicolaï and Bernard Comrie for inviting me to take part. I gratefully acknowledge Paul Kockelman's contribution in extended discussion as I was writing the paper. For comments on a written version, I would also like to thank Rob Boyd, Bill Croft, Michael Cysouw, Mark Dingemanse, Michael Dunn, Peter Richerson, and Dan Sperber. These commentators are not to be held responsible for any infelicities of form or content. This work is supported by the Max Planck Society.
} 
recurrent pattern of grammatical functionality in MSEA languages, namely the use of an erstwhile verb meaning 'acquire' for aspectual-modal functions in a range of syntactic positions. These patterns may be represented schematically along the following lines:

(1) He acquire fish. 'He got fish.'

(2) He fry fish acquire. 'He can fry the fish.'; 'He managed to fry the fish.'

(3) He fry fish acquire fast. 'He fried the fish fast.'

(4) He acquire fry fish. 'He did fry the fish.'; 'He got to fry the fish.'

There are uncanny (though not perfect) similarities between language after language in MSEA in the realization of this pattern. Enfield (2003) gives detailed descriptions of the phenomenon in Lao (SW Tai), Hmong (Hmong-Mien), Kmhmu Cwang (N. Mon-Khmer), Vietnamese (E. Mon-Khmer with heavy Sinitic influence), and Khmer (E. Mon-Khmer with heavy Tai influence), along with further data on some 20 other languages of the region. The parallelism is striking, particularly given the genealogical diversity of the languages, and the relatively low level of cognacy among lexical exponents of the 'acquire' morpheme across these languages (Enfield 2003:349).

A goal of historical-comparative linguistics in cases like this is to distinguish between possible accounts for shared structure between languages, particularly insofar as it makes a difference for our understanding of associated patterns in social history (migration, socio-economic relations, etc.). Often, this is expressed as a binary distinction between inheritance and diffusion (cf. Aikhenvald \& Dixon 2001). There are, however, at least four ways in which language systems can share structure (Enfield 2003:367-8):

I. Vertical: A and B share structure because they inherited it from a common ancestor.

II. Horizontal: A and B share structure because it was borrowed from one to the other (or from a third) through social contact between speech communities.

III. Internal: A and B share structure because it developed independently in each system, through the same natural processes of change.

IV. Accidental: A and B share structure through unlikely coincidence.

Much current work in historical and comparative linguistics is aimed at establishing ways to examine contemporary states of affairs and correctly infer the chains of events which led to them, ideally distinguishing between competing accounts I-IV. Rather than offer diagnostics of this kind (if only I could), my aim here is to characterize underlying processes by which these different kinds of relation might arise. The essential claim is that in order to understand the underlying processes, we need to make explicit the link between language as a psychological phenomenon on the one hand, and as a cultural, population-level phenomenon on the other.

\section{Linguistic epidemiology: not a metaphor}

Epidemiology typically refers to the (study of the) distribution of disease or illness in a population, for example the spread of a virus. I use the term here more generally for the (study of the) distribution in a population of any kind of variant (e.g. virus, genetic marker, pattern of behaviour, type of artefact) through a process of social/interpersonal transmission. Previous authors who have taken similar or related perspectives include Sperber (1984, 1996), Kortlandt (1985), Keller (1994), Nettle (1999), Croft (2000), Van Driem (2001), Mufwene (2001), Boyd \& Richerson 
(2005), Richerson \& Boyd (2005), among others. A linguistic variant could be any kind of conventionalized type form-meaning mapping at any level of abstraction including words, morphemes, constructions, and idioms. By this account, a single type of epidemiological process of social transmission can be viewed in one frame as diffusion (if it results in new distribution of the variant) and in another frame as maintenance (if it reinforces current distribution).

To speak of linguistic processes in epidemiological terms is to say that individual types of linguistic variant are circulated in populations by chains of events in which one individual exposes another to a variant, such that the second individual may in turn expose yet another to the same variant, furthering the process indefinitely. A key task for the epidemiologist is to track these causal chains, including the relevant conduits and filters, which determine a variant's spatio-temporal career in a historical population. Central to such causal chains are events of interpersonal contact between individual carriers of a variant. In the case of language, the contact in question usually entails physical co-presence, either in face-to-face conversation or other kind of exchange, or at the very least through overhearing when in spatial proximity (e.g. in a marketplace or bus). In a small proportion of the world's languages, literacy makes it possible for there to be significant spatiotemporal distance between the production of a sign and its comprehension, showing that while contact typically entails co-presence of speaker/signer and hearer/interpreter, it need not (cf. Lass 1997:185). There must, however, be direct contact between sign and interpreter, otherwise there can be no semiotic process (Peirce [1940] 1955, Kockelman 2005).

Before proceeding, let me dispel one possible interpretation of this type of account of the population-level distribution of linguistic variants. Linguistic variants are not agents which strive to colonize their human carriers, nor do humans passively 'catch' these variants or 'infect' others, as if speaking to someone were literally like sneezing on them. In order to play a role in the diffusion of a linguistic variant, not only must an individual have been exposed to the variant (and thereby have constructed a mental representation of it), he or she must also be motivated to (re)produce it in some public behaviour, thereby exposing others to it in turn. A speaker's public production of the linguistic process in question is enabled and constrained by a range of social and strategic factors (discussed below). The circulating linguistic variants themselves are not agents in the process of linguistic epidemiology.

\section{The units of transmission: variants, not languages}

There is no type of single event through which 'a language' as an entire structured system is socially transmitted. It is only through exposure to fragments of language, one chunk at a time, that we are able to build descriptions of whole language systems, either in learning languages (e.g., as children or as second-language learners) or in documenting them (e.g., as grammarians). Causal processes in the dynamic circulation of language are at the level of utterances and linguistic items (Nettle 1999, Croft 2000), not at the level of languages. As has often been pointed out-nowhere more eloquently and forcefully than by Le Page \& Tabouret-Keller (1985) - the notion of a language is essentially an ethnic, ideological, and political one. To understand the distribution of linguistic structure at a population level, we are primarily concerned with the spatio-temporal distribution of individual elements of a language system. Any notion that 'languages' are distributed in populations, while true in certain senses (see below), is secondary to the distribution of individual linguistic variants.

Let me clarify a few points before elaborating in more detail.

First, to speak of linguistic variants as 'things' is a convenient fiction. If we speak of the distribution in a population of a word or other linguistic form, we are in fact referring to the distribution of a communicative, collaborative practice of employing, and responding to, a word or linguistic form. Linguistic variants have dynamic properties due to the presence not just of signs (or 
signifiers) and their objects (or signifieds), but also of the responsive interpretants which display and in part constitute their meaning (Peirce [1940] 1955). A linguistic variant is a type of process, not a type of thing.

Second, to adopt an item-based approach does not imply that languages are unsystematic bundles of loose, freely-circulating pieces. Nevertheless, such an approach does have to provide an explicit account for the mapping of item to structured system (more on this in sections 6 and 7 , below).

Third, the notion of 'a language' can play a direct role in processes of transmission, in two important ways; first, to the extent that speakers' metalinguistic awareness and ethnolinguistic identity can be an enabling or constraining factor (e.g., where speakers' identification of a linguistic variant with 'a language' affects the variant's model bias); second, to the extent that individuals construct mental representations of higher-order structured systems consisting of large inventories of interconnected linguistic items, where these higher-order systems play an enabling or constraining role as structural contexts for individual linguistic variants. This second sense of 'a language' refers to the individually-situated psychological object otherwise known as a grammar (in the sense of Chomsky 1965).

\section{Transmission biases}

If a linguistic variant is conventional in a community, it can only have become that way through a prior historical process of innovation and successful social diffusion. That is, the convention was once an innovation, and through a process of adoption by community members has become a norm. Each variant has its own epic story. The process of community-wide adoption and maintenance of social practice involves a complex set of mechanisms familiar from work in sociology on the social diffusion of innovation (Rogers 1995; see also Enfield 2003:2-21, 2005:194-7), and more recent work in evolutionary anthropology (e.g., Boyd \& Richerson 2005). Among these mechanisms are transmission biases (Richerson \& Boyd 2005:69 and passim). These are forces which work as conduits or filters for the success or failure of a cultural variant in going from innovation to conventional norm, and in subsequent maintenance or loss of its status as conventional norm. In a semiotic model of linguistic transmission-one which views linguistic variants as processes involving speakers, signs, interpreters, and communicative acts as much as they involve mental representations - the relevant biases will involve all elements of the semiotic process. This includes signers, signifiers, signifieds, responses and the interpreters that enact these.

\subsection{Biases defined by properties of people or relations between people}

A threshold bias is associated with personality differences among potential adopters of an innovation. Individuals vary as to their degree of readiness to reproduce an innovative and therefore socially marked behaviour (Granovetter 1978, Granovetter \& Soong 1983). These threshold differences allow us to distinguish between innovators, early adopters, late adopters, and laggards (Rogers 1995). This bias based on variation in properties of potential adopters combines with a sociometric bias, associated with differences in individuals' degrees of connectedness within social networks. An innovator (i.e., someone with a lower adoption threshold) will not necessarily be an effective conductor of innovation within a population. Much will depend on his number of social connections (co-varying with the 'strength' of those connections; Granovetter 1973), which determines how widely he will advertise the practice in question. Related to this, a model bias arises from publicly perceived properties of a person who publicly reproduces an innovation. The social status or identity (prestige, charisma) of an individual who acts as a carrier of the innovation will affect others' willingness or desire to reproduce it (thereby potentially being seen to identify with that person, or that type of person). This in turn is related to a conformity bias by which, all things being equal, people will tend to adopt the same practices as those with whom they socially identify 
(Boyd \& Richerson 2005; cf. Simon 1990). The conformity bias is particularly strong in early socialization (e.g., first language acquisition), and is a key mechanism in channelling genetic and cultural material along similar spatial-historical paths.

\subsection{Biases defined by properties of variants or relations between variants and people}

Orthogonal to the above biases defined through properties of people and their sociometric statuses are biases associated with properties of innovations themselves. By a powerful content bias, if an innovation is particularly useful or advantageous, it will be intrinsically more attractive to potential adopters and hence more likely to be reproduced (independent of other biases such as who models it). A frequency bias arises from the relative ubiquity of an innovation's production (in turn a possible function of other biases such as the sociometric bias).

\subsection{Context bias: defined by relations between variants and their contexts}

The biases discussed in sections 4.1 and 4.2, above, provide an array of parameters in a possibility space whose enormity is a function of the large social group size typical of human populations, and of the massive cultural systems which emerge within these populations. The notion of cultural system tends to be absent from the sociology and anthropology sources mentioned above. While those sources are well aware of one sort of micro-macro relation, namely that between the individual person (micro) and his social group (macro), there is another sort of micro-macro relation which is just as important. This is the relation between individual diffusible variants at the micro end, and the larger systems of such variants into which any given variant must fit, at the macro end. Language is an archetypal illustrative example. At the micro end are words and other linguistic items which may be individually learned and diffused. At the macro end are the giant system structures we know as 'languages' (grammar-lexicons), into which diffusing micro items must fit (or be fitted).

While this notion of system fit is perhaps most readily understood in the case of language, it is not exclusive to language. It arises naturally in culture, too, through a basic relation of contextualization (Kockelman 2006). The idea is simple. Any kind of meaningful structure, be it a word, an artefact, a type of social relation or whatever, will presuppose some kind of contextual frame into which it properly fits, and without which it will not function appropriately. Any variant presupposes a contextualizing structure, and the presence or absence of this structure will constitute a conduit or filter for transmission of the innovation. We may call this a context bias, defined by the kind of structure an innovation presupposes for its proper function.

Take for example the bicycle. The likelihood of this technological innovation being adopted is heightened by a strong content bias. Riding a bicycle has enormous advantages over, say, walking. However, a context bias provides a potentially fatal filter on the likelihood of the bicycle being adopted by a given group. For the bicycle, the type of contextualizing structure appropriate for proper employment of the innovation includes the kind of path upon which it may be ridden. Without such paths (e.g. in a mountainous, forested environment), the innovation is not appropriately contextualized, and thereby loses its otherwise great appeal.

In linguistics the principle of context bias is readily understood with reference to dependency relations defined by language-specific grammatical structure. While it is widely said that there are no intrinsic constraints on the kinds of linguistic structures that can be borrowed from one language to another (Thomason 2001), there are tendencies, both relative and absolute. In general, linguistic items which are least dependent on language-specific structure diffuse relatively freely. An example is the interjection. The kinds of structures which properly contextualize interjections are relatively independent of specific languages. Interjections occur as complete utterances in themselves (Bloomfield 1933:176). This means that they are properly contextualized not by language-specific grammatical structures, which may differ radically from social group to social group, but by certain 
kinds of environmental situation or discourse moment. The kinds of linguistic structure which are less likely to diffuse tend to be those which are contextualized by highly language-specific structures (cf. Myers-Scotton 2002).

We shall revisit the context bias in Section 7, below, where it is of use in accounting for the micro-macro mapping of variants to systems.

\section{Vertical versus horizontal transmission}

Processes of change described by linguists as internal versus external are identical in so far as they must ultimately be effected by the same set of population-level processes which constitute and regulate the diffusion of innovation (Enfield 2003:368, 2005:190-198). The substance of a distinction between internal and external change relates primarily to a difference in source of an innovation. The same point can be made for the distinction between vertical and horizontal transmission in linguistic and cultural history (Cavalli-Sforza \& Feldman 1981). Processes of vertical and horizontal transmission are fundamentally alike in that they involve the adoption by an individual of a variant, through exposure to, and learning of the variant, and subsequent, sociallymediated motivation to reproduce it. But while they involve the same process of actuation, this is not to say that vertical and horizontal transmission are wholly identical. Horizontal transmission involves the adoption of variants from ethnic groups other than one's own, typically through social contact in adulthood (or at least after early childhood). Vertical transmission involves the adoption of variants from within one's own ethnic group, often one's own kin, typically in infancy and early childhood. Most significant language learning is like this, since our learning of the majority of typological structure of a language is well in place by around age 4, well before we gain social independence and the possibility of sustained interaction with outside social groups.

Clearly, it makes a significant difference to our successful adoption of a variant whether we learn it in early childhood or in later life. In language, for example, this difference corresponds to a hard-to-fake and easy-to-detect distinction between native-speaker competence and secondlanguage (or second-variety) competence (Nettle \& Dunbar 1997). An individual's first language system is acquired through vertical transmission, and subsequent encounters with other systems are filtered through a system which is already in place.

Another significant difference between the two types of transmission is the social-markedness status of the adoption of variants in infancy and early childhood (vertical) as opposed to later in life (horizontal). Variants adopted early in life are not adopted as innovations, but as norms, soaked up by means of a kind of group-identificational docility (Simon 1990; cf. Richerson \& Boyd 2005, Gergely \& Csibra 2006), that is, through a putatively innate propensity to unquestioningly adopt the practices of those with whom one socially identifies. This was referred to above as a conformity bias. The result of vertical transmission is that our primary cultural learning is from those with whom we are most likely to share genetic material. And in turn, once natively socialized, to adopt linguistic or cultural variants from another social group is to adopt an innovation (not a norm), which by virtue of its social markedness becomes a new ball game for the individual who is adopting linguistic and other cultural variants.

\section{Centripetal forces of system structuration}

I have argued that as products of general mechanisms of social diffusion, each linguistic convention in a community has its own individual history. Each word, each morpheme, each construction has followed its own historical path to population-level conventionality. As Bloomfield (1933:444) put it, 'individual forms may have had very different adventures'. This suggests we can discard the view that genealogical relations are qualitatively distinct from relations of diffusion, since linguistic variants are always socially diffused. But as any linguist knows, the genealogical view works well in practice, and languages are far from being mere bundles of items. A language is 
a set of linguistic conventions which coheres as a large, structured, systematic whole, with both psychological and intersubjective reality. ${ }^{2}$ Psychologically, languages exist as idiolects, embodied (i.e., cognitively represented and neurologically instantiated) in individual speakers' minds (and brains/bodies). They are structured, systematic representations of large sets of interrelated linguistic variants. Intersubjectively, languages exist at a community level to the extent that individuals' idiolects are effectively alike in structure and content, as evidenced by normative practices of signifying and interpreting.

When individuals' language systems are effectively (though never exactly) shared, ${ }^{3}$ it is because a large proportion of these variants are channelled, in a giant set, along the same historical pathways. This creates the impression that a whole language is passed down, transcending lifetime after lifetime of the individuals who learn and embody the system. This is the point made by Thomason \& Kaufman (1988): Normal social conditions enable first language learners to construct idiolects which effectively match those of the people they learn from-i.e., those who share the same household and immediate social environment (and who are most likely to share genetic material). Normal transmission allows historical linguists to abstract from the fact that each linguistic variant has its own distinct career, instead treating the whole language as having a single spatial-historical trajectory. In many cases this is a reasonable (indeed successful) methodological presumption (cf. Haspelmath 2004). The contribution of work such as Le Page \& Tabouret-Keller (1985), and Thomason \& Kaufman (1988), has been to show that in situations other than those of normal transmission (the kinds of social context in which creoles emerge), linguistic variants do not always travel together, but may follow detectably different paths, ${ }^{4}$ making visible what is always true but usually obscured: Each linguistic variant has its own history.

\section{Centripetal forces promoting system continuity}

Genealogical continuity in language change is typically taken to be the norm, and special explanations are demanded for the relative permeability of linguistic systems through language contact, and the forces which prise components of languages apart. But we must equally ask: How to explain the relative impermeability of linguistic systems in normal circumstances? ${ }^{5}$ What are the forces which cause linguistic variants to follow en masse a single path of diffusion and circulation?

\section{1 'Bundling' of sets of items through sociometric closure}

A first centripetal force may be termed sociometric closure, arising from a trade-off between strength and number of relationship ties in a social network. An individual speaker must commit a certain amount of time to maintaining a given social relationship, and since time is a finite resource, this puts a structural constraint on the possible number of such relationships one can maintain in a social network (Hill \& Dunbar 2003). The result is a relatively closed circulation of currency within

\footnotetext{
${ }^{2}$ By 'structured', I mean that the systems display syntagmatic and paradigmatic organization which provides evidence for classes of forms and their distributional patterns (Bloomfield 1933). As ordinary speakers, we do not encounter these classes as such, but only as indexed by the combinatoric patterns exemplified in token utterances.

${ }^{3}$ When a full set of variants is not exactly shared by two people, this will not necessarily be taken to signal a difference in which language they speak. Within ethnic or other social group boundaries, such differences might go undetected or might be ignored, or may mark mere sociolinguistic distinctions. When detected across social group boundaries, the same differences may be sufficient for claiming that entirely different languages are spoken.

${ }^{4}$ Michael Dunn points out (in personal communication) the analogy with human genetic material: The historical trajectories of mitochondrial DNA and Y chromosomes can be quite distinct (Dunn et al. 2007).

${ }^{5}$ Similarly, Sperber has pointed out in an epidemiological model of culture that stability in conventional systems is no less in need of explanation than variation or change (cf. Sperber \& Hirschfeld 2004).
} 
a social economy of linguistic variants, causing individuals' inventories of variants (i.e., their idiolects) to overlap significantly (or be effectively identical) within social networks. This helps to account for how individuals in regular social association can have a common set of variants, but it does not account for the tightly structured and systematic types of relations between those variants. We turn now to the reflexive forces of structuration inherent to grammatical organization at the utterance level, which works on the same mechanism as the context bias, explicated in Section 4.3, above.

\subsection{Item-utterance fit}

A key conduit and filter for grammatical structure is grammatical structure itself, as introduced in the discussion of context bias in Section 4.3, above. The utterance is the key structural locus, providing narrow contextualization for linguistic variants, and serving as the essential ratchet between item and system. By 'utterance' I mean a burst of articulatory activity which lasts typically for a few seconds, with recognizable formal and pragmatic completeness, constituting a single 'move' or communicative action in discourse. This corresponds loosely to the primitive unit of speech production in psycholinguistics (e.g., Levelt 1989), the intonation unit in research on spoken discourse (e.g., Chafe 1994), the turn-constructional unit in conversation analysis (Sacks et al 1974), and the clause in syntactic typology (e.g., Foley \& Van Valin 1984).

Most linguistic variants do not appear in isolation but are embedded in grammatically complex utterances. The utterance may be thought of as a basic frame for replication of linguistic variants (cf. Croft 2000). I shall use the term item-utterance fit to refer to the structural fit between diffusible types of linguistic item and the token utterances in which they appear. Item-utterance fit is a potential conduit or filter for structuration, via relations of dependency through contextualization of linguistic variant units by the linguistic utterance units in which they are framed in token speech events. Variants and utterances are both encountered as tokens, but only individual variants are necessarily tokens of types. That is, the variant units in a given utterance are replicas (in the semiotic sense of Peirce [1940] 1955:102), since they are recognizable instantiations of existing type conventions. By contrast, the utterance units themselves are not replicas but singularities (Kockelman 2005:241). That is, whole utterances are tokens but not usually tokens of types. So, utterances are not units for replication (unless the whole utterance happens also to be a type such as a pre-packaged idiom or an interjection). In this way, an utterance provides an incorporating and contextualizing frame for the diffusion of replicable linguistic variants. We should expect there to be analogous relations to item-utterance fit in the domain of culture (think, for instance, of systems of social relations in kinship, or systems of artifactual relations in household and village). ${ }^{6}$

It is useful in this connection to draw attention to a critical revision to the standard Saussurean 'form-meaning mapping' version of the linguistic variant (following Mel'čuk 1968, Pollard \& Sag 1987:51, Evans in press). In addition to phonological form and semantic content, a linguistic variant also has combinatoric properties. Any token of a linguistic variant embedded in an utterance should exemplify, and thereby display and help to entrench, those combinatoric patterns. This is our front door key into the mansion of linguistic structure: any information about the combinatorics of a variant will supply information on further (classes of) variants (i.e, those with which the first variant is combinatorially related). With enough data points, we may establish structural-distributional profiles for all the variants we have, thereby inferring the structure of entire grammatical systems (Bloomfield 1933, Tomasello 2003).

\footnotetext{
${ }^{6}$ On semiotic principles of incorporation and contextualization in language and culture, see Kockelman (2006).
} 


\section{Concluding discussion}

An epidemiological approach to the dynamics of language contact and change attempts to explicate the causal mechanisms which fall victim to the methodological abstractions of standard linguistics. It places language naturally within a general account of cultural evolution (cf. Croft 2001, Richerson \& Boyd 2005). Further reasons this exercise is worthwhile include the following. First, it uses the same analytical machinery in analyzing innovation and change as it does in analyzing maintenance and continuity. It shows that language diffusion and language change each involve both processes of diffusion and change. Second, by this account it is entirely natural that different elements of a language should have distinct spatial-historical paths. It draws attention to the need to explain how it is that different elements of a language should follow the same spatialhistorical paths. Third, this account gives equal significance to structural and social forces in language change, with neither inherently privileged. Fourth, the account makes it entirely natural that teasing apart contact effects versus inheritance effects in contemporary language structure should be maddeningly difficult, thanks to the unpredictability of (finite yet enormous) emergent patterns of social diffusion in large populations. And lastly, this account allows us to make explicit some of the key differences between the four types of system relatedness discussed above, showing that they are far more closely related than typically supposed:

\begin{tabular}{lllll}
\hline \hline $\begin{array}{l}\text { System } \\
\text { Relation }\end{array}$ & $\begin{array}{l}\text { Embodied by } \\
\text { individuals via } \\
\text { direct adoption } \\
\text { of variant? }\end{array}$ & $\begin{array}{l}\text { Established at } \\
\text { population level by } \\
\text { epidemiological } \\
\text { process? }\end{array}$ & $\begin{array}{l}\text { Pragmatic } \\
\text { markedness of } \\
\text { adoption? }\end{array}$ & Source of variant? \\
\hline \hline Vertical & yes & yes & $\begin{array}{l}\text { Unmarked (by } \\
\text { docility) }\end{array}$ & $\begin{array}{l}\text { Kin and near-kin, in } \\
\text { infancy/childhood }\end{array}$ \\
\hline Horizontal & yes & yes & $\begin{array}{l}\text { Marked (innovation, } \\
\text { out-group) }\end{array}$ & $\begin{array}{l}\text { Ethnic others, beyond } \\
\text { infancy/childhood }\end{array}$ \\
\hline Internal & yes & yes & $\begin{array}{l}\text { Weakly marked } \\
\text { (innovation, } \\
\text { motivated) }\end{array}$ & $\begin{array}{l}\text { Pragmatic extension } \\
\text { from existing structure, } \\
\text { natural meaning }\end{array}$ \\
\hline Accidental & yes & yes & $\begin{array}{l}\text { Marked } \\
\text { (innovation) }\end{array}$ & Random \\
\hline \hline
\end{tabular}

Figure 1. Four types of account for common structure between languages, and some of their features.

I have tried to stress that the various types of accounts for how a variant may be common across systems in fact share most of their important properties. To understand any of these processes, we need a population-level account of diffusion and maintenance of cultural variants within the context of social systems (of which individual people are micro-level units) and cultural systems (of which diffusible variants are micro-level units). I hope in particular that by drawing attention to the role of multiple, distinct transmission biases in this account, we may be a step closer to characterizing a true anatomy of micro-macro relations in socio-cultural systems. 


\section{References}

Aikhenvald, A. Y, \& Robert M.W. Dixon, (eds.), 2001. Areal diffusion and genetic inheritance: problems in comparative linguistics. Oxford: Oxford University Press.

Boyd, Robert, \& Peter J. Richerson. 2005. The origin and evolution of cultures. New York: Oxford University Press.

Bloomfield, Leonard. 1933. Language. Chicago: Chicago University Press.

Cavalli-Sforza, Luigi L. \& Marcus W. Feldman, 1981. Cultural Transmission and Evolution: A Quantitative Approach. Princeton: Princeton University Press.

Chafe, Wallace. 1994. Discourse, consciousness, and time: the flow and displacement of conscious experience in speaking and writing. University of Chicago Press, Chicago.

Chomsky, Noam A. 1965. Aspects of the theory of syntax. Cambridge, Mass: MIT Press.

Croft, William. 2000. Explaining language change: an evolutionary approach. Harlow: Longman.

Dahl, Östen. 2006. An exercise in "a posteriori" language sampling. Ms, Stockholm University Linguistics Department.

Dunn, Michael, Niclas Burenhult \& Nicole Kruspe. 2007. Evolutionary approaches to the prehistory of Aslian languages. Presentation at workshop Mon-Khmer Linguistics: New Developments, MPI Nijmegen, 16-17 April, 2007.

Enfield, Nicholas J. 2003. Linguistic epidemiology: semantics and grammar of language contact in mainland Southeast Asia. London: Routledge.

Enfield, Nicholas J. 2005. Areal linguistics and mainland Southeast Asia. Annual Review of Anthropology, Vol. 34:181-206.

Evans, Nicholas R. D. in press. Semantic typology. In Jae Jung Song (ed.), The Oxford Handbook of Linguistic Typology. Oxford: Oxford University Press.

Foley, William A. \& Van Valin Jr, Robert D. 1984. Functional syntax and universal grammar. Cambridge: Cambridge University Press.

Gergely, Georgy, \& Gergely Csibra. 2006. Sylvia's recipe: the role of imitation and pedagogy in the transmission of cultural knowledge. In N. J. Enfield \& Stephen C. Levinson (eds.), Roots of human sociality: culture, cognition, and interaction. 229-255. Berg, London.

Granovetter, Mark. 1973. The strength of weak ties. American Journal of Sociology 78: 1360-1380.

Granovetter, Mark. 1978. Threshold models of collective behaviour. American Journal of Sociology 83:1420-1443.

Granovetter, Mark, \& Soong, Roland. 1983. Threshold models of diffusion and collective behaviour. Journal of Mathematical Sociology 9:165-179.

Haspelmath, Martin. 2004. How hopeless is genealogical linguistics, and how advanced is areal linguistics? Studies in Language 28.1:209-223.

Hill, Russel A. \& Dunbar, Robin, 2003. Social network size in humans. Human Nature 14:53-72. 
Keller, Rudi. 1994. On Language Change: The Invisible Hand in Language. London - New York: Routledge.

Kockelman, Paul. 2005. The semiotic stance. Semiotica 157.1-4:233-304.

Kockelman, Paul. 2006. Residence in the world: Affordances, instruments, actions, roles, and identities. Semiotica 162.1-4:19-71.

Kockelman. Paul. 2007. Agency: The Relation between Meaning, Power, and Knowledge. Current Anthropology 48.3:375-401.

Kortlandt, Frederik Herman Henri. 1985. A parasitological view of non-constructible sets. In Ursula Pieper \& Gerhard Stickel (eds.), Studia linguistica diachronica et synchronica: Werner Winter sexagenario anno MCMLXXXIII gratis animis ab eius collegis, amicis discipulisque oblate, 477-483. Berlin: Mouton de Gruyter.

Lambrecht, Knud. 1994. Information structure and sentence form: topic, focus and the mental representations of discourse referents/grammatical relations. Cambridge: Cambridge University Press.

Lass, Roger. 1997. Historical linguistics and language change. Cambridge: Cambridge University Press.

Le Page Robert B. \& Tabouret-Keller, Andrée. [1985] 2006. Acts of Identity. Creole-based approaches to language and ethnicity. InterCommunications \& E.M.E. $\left(1^{\text {rst }}\right.$ ed. Cambridge: Cambridge Univ. Press).

Levelt, Willem J. M. 1989. Speaking: From Intention to Articulation. Cambridge, MA: MIT Press.

Mel'cuk, Igor. 1968 [1976]. Stroenie jazykovyx znakov i vozmozhnye formal'nosmyslovye otnoshenija mezhdu nimi. Izvestija AN SSR, Serija lit. I jaz., 1968, vyp. 5. English translation: The structure of linguistic signs and possible formal-semantic relations between them. Das Wort. Wilhelm Fink Verlag: München. 89-114. [Cited in Evans in press.]

Mufwene, Salikoko S. 2001. The Ecology of Language Evolution. Cambridge: Cambridge University Press.

Myers-Scotton, Carol. 2002. Contact linguistics: Bilingual encounters and grammatical outcomes. Oxford: Oxford University Press.

Nettle, Daniel. 1999. Linguistic diversity. Oxford: Oxford University Press.

Nettle, Daniel \& Dunbar, Robin. 1997. Social markers and the evolution of reciprocal exchange. Current Anthropology 38.1:93-99.

Peirce C. Sanders. 1940. The Philosophy of Peirce: Selected Writings. Justus Buchler (ed.). New York: Dover. Rpt. as Philosophical Writings of Peirce. 1955.

Pollard, Carl, \& Ivan Sag. 1987. Information-based syntax and semantics. Stanford: CSLI.

Richerson, Peter J. \& Robert Boyd. 2005. Not by genes alone: how culture transformed human evolution. Chicago: University of Chicago Press.

Rogers, Everett M., 1995. Diffusion of innovations. New York: The Free Press. 
Sacks, Harvey, Emanual A. Schegloff, \& Gail Jefferson. 1974. A simplest systematics for the organization of turn-taking for conversation. Language 50.4:696-735.

Simon, Herbert A. 1990. A mechanism for social selection and successful altruism. Science 250:1665-1668.

Sperber, Dan. 1985. Anthropology and psychology: towards an epidemiology of representations. Man 20:73-89.

Sperber, Dan. 1999. Conceptual Tools for a Natural Science of Society and Culture. RadcliffeBrown Lecture in Social Anthropology.

Sperber, Dan. 2006. Why a deep understanding of cultural evolution is incompatible with shallow psychology. In N. J. Enfield \& Stephen C. Levinson (eds.), Roots of human sociality: culture, cognition, and interaction. 431-449. Berg, Oxford.

Sperber, Dan \& Hirschfeld, Lawrence A. 2004. The cognitive foundations of cultural stability and diversity. Trends in Cognitive Sciences 81: 40-46.

Thomason, Sarah G. \& Terrence Kaufman. 1988. Language contact, creolization, and genetic linguistics. Berkeley: University of California Press.

Thomason, Sarah G. 2001. Language Contact: An Introduction. Edinburgh: Edinburgh University Press.

Tomasello, Michael. 2003. Constructing a language: a usage-based theory of language acquisition. Cambridge, MA: Harvard University Press.

van Driem, George. 2001. Languages of the Himalayas: An Ethnolinguistic Handbook of the Greater Himalayan Region with an Introduction to the Symbiotic Theory of Language (2 vols.). Leiden: Brill. 